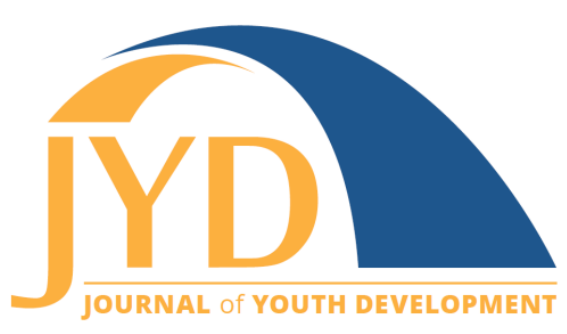

http://jyd. pitt. edu/ | Vol. 13 Issue 3 DOI 10.5195/jyd.2018.595 | ISSN 2325-4017 (online)

\title{
Teens as Teachers: Positive Outcomes and Recommendations for Promoting Healthy Nutrition in Adolescents
}

\author{
Elizabeth H. Weybright \\ Washington State University \\ elizabeth.weybright@wsu.edu \\ AnaMaria Diaz Martinez \\ Washington State University \\ anamaria.martinez@wsu.edu \\ Gary Varrella \\ Washington State University \\ gvarrella@wsu.edu \\ Mary Katherine Deen \\ Washington State University \\ mdeen@wsu.edu

\section{Kevin Wright} \\ Washington State University \\ wrightkc@wsu.edu
}

\section{Abstract}

The prevalence of overweight and obese status in adolescence points to a need to identify and broadly disseminate effective approaches promoting healthy eating. One promising approach engages teens as teachers to implement a nutrition education curriculum for younger youth. This article highlights qualitative evaluation results of a cross-age peer-teaching program on teen teachers. Results strengthen our knowledge base of cross-age peer teaching and inform policy and practice implications. Teens experienced greater internalization of curriculum content as evidenced by increased knowledge, improved behaviors, and overcoming barriers to healthy eating. These findings are grounded in social learning theory. To disseminate cross-age peer teaching within youth-serving organizations, we recommend the

(c) $\mathbf{E Y}$ New articles in this journal are licensed under a Creative Commons Attribution 4.0 License. This journal is published by the University Library System, University of Pittsburgh and is cosponsored by the University of Pittsburgh Press. The Journal of Youth Development is the official peer-reviewed publication of the National Association of Extension 4-H Agents and the National AfterSchool Association. 
Teen Teacher Nutrition Outcomes

use of an evidence-based framework to guide program implementation and the development of policy to ensure intentional teen teaching opportunities.

Key words: teens as teachers, nutrition, youth-adult partnerships, social cognitive theory

\section{Introduction}

The number of overweight and obese adolescents has increased in the past decade despite a number of both focused and widespread efforts to promote healthy nutrition in adolescence (Centers for Disease Control \& Prevention, 2015). One successful approach in promoting health across a broad range of outcomes is the use of cross-age peer teaching (Smith, 2014). However, cross-age peer teaching is not widely used in nutrition education (Coleman et al., 2011). This article focuses on a cross-age, peer-teaching nutrition education program implemented within Extension 4-H Youth Development. Specifically, the program model engaged teens as teachers who taught younger youth a nutrition curriculum. We were interested in understanding if the teens gained knowledge and made behavior changes related to nutrition as a result of being teen teachers. Based on social cognitive theory (Bandura, 1977), we expect program participation by teens will improve teen nutrition knowledge and behavior as a result of learning and teaching a curriculum to younger youth. This program, as well as its evaluation and results, contributes to the broader literature on the positive outcomes experienced by cross-age teen teachers. To encourage adoption by other youth-serving organizations, we provide practice and policy implications for implementing a cross-age teaching program.

\section{Adolescent Nutrition}

Over the past four decades, the rates of childhood overweight and obesity in the United States have more than doubled (Lobstein et al., 2015). Although childhood obesity rates have remained stable at about $17 \%$ since 2011 , the rate of obese adolescents is higher than childhood rates at 20\% (Ogden, Carroll, Fryar, \& Flegal, 2015). Long-term, childhood and adolescent obesity may result in chronic health conditions and costly health care needs. Adolescence is a critical developmental stage as many health-related behaviors are established that will carry into adulthood (Sawyer et al., 2012). This situation makes clear that promoting healthy eating knowledge and behavior during adolescence must be a public health priority for community agencies (Pate et al., 2000; U.S. Department of Health and Human Services and U.S. Department of Agriculture, 2015). 


\section{Cross-Age Peer Teaching}

One promising approach to promoting healthy eating knowledge and behavior in adolescence is through cross-age peer teaching (Arnold et al., 2016). Cross-age peer refers to a relationship between two peers of the same generation where one peer is slightly older (e.g., 2 to 3 years older; Lee \& Murdock, 2001) than the other (Karcher, 2005). In the current program, teens (ages 14 to 19) taught younger youth (ages 8 to 12). Therefore, we refer to teens engaging in cross-age peer teaching as "teen teachers." Using social cognitive theory (Bandura, 2004) as a theoretical foundation and Lee and Murdock's (2001) Teens as Teachers Essential Elements as a framework, we expected teens who served as nutrition educators for younger youth would experience improvements in their own healthy eating knowledge and behaviors.

Social cognitive theory (SCT; Bandura, 2004) is used widely in nutrition education programs. This theory acknowledges that behavior is influenced by environmental and personal factors, as well as the interaction between these factors (Hoelscher, Evans, Parcel, \& Kelder, 2002). SCT is especially useful in adolescent-focused programs, as it can account for how developmental processes and experience interact to influence behavior. Specifically, SCT suggests an individual's self-efficacy, or belief in one's ability to accomplish a task, is a critical precursor to engaging in healthy behaviors. Based on SCT, being a teen teacher promotes self-efficacy and greater confidence in curriculum content and teaching abilities that, in turn, influences one's behavior (Bandura, 1998; Smith, 2014).

Lee and Murdock (2001) conducted a comprehensive study of teens in cross-age teaching roles who taught younger children in 13 after-school programs. Based on their results, they identified 10 essential elements, or best practices, that support positive outcomes for teen teachers as well as the younger youth that they teach.

1. Dedicated Adults Who Support Teens: Passionate, committed adults dedicated to youth-adult partnerships giving the teens opportunity to take the lead

2. Active Teen Recruitment: Purposeful marketing of the opportunity to targeted groups of teens and aligning the selection process with career readiness skills (e.g., job interviews)

3. Strong Curriculum: In-depth curriculum with well-written specific directions that incorporates hands-on learning activities focused on one subject matter

4. Initial Training: Orientation to the program and initial training 
Teen Teacher Nutrition Outcomes

5. Ongoing Training and Support: Even more important than the initial training is the attention to ongoing subject matter, teaching skills, and processing time throughout the program

6. Attention to Details: Such as communication processes, meeting the basic needs of the teen teachers and younger youth (e.g., food) and safety and emergency procedures

7. Recognition and Reward: These vary depending on needs of the teens from verbal praise to certificates or letters of recommendations to stipends

8. Team Building: Intentionally including time for team interaction and learning

9. Setting Teens Up for Success: Gradually increasing teen responsibility as they grow in experience

10. Feedback and Evaluation: Providing feedback in a variety of methods including observation notes, team and individual reflection time, and written evaluations

Teen teachers not only promote positive outcomes among those they teach but also "learn by doing," a 4-H tradition (Enfield, 2001). Previous studies grounded in social cognitive theory find teens experience positive outcomes related to curriculum content, skill development, and positive youth development. For example, after teaching a nutrition curriculum, teen teachers increased consumption of fruits, vegetables, and lower-fat foods (Story, Lytle, Birnbaum, \& Perry, 2002). Others have identified teen outcomes of increased self-confidence (Lee \& Murdock, 2001) and skill development related to teaching, communication, leadership, and emotional intelligence (e.g., respecting others; Weybright et al., 2016).

\section{Youth Advocates for Health Teens as Teachers Program}

Youth Advocates for Health (YA4-H!; Flesch, Lile, \& Arnold, 2015), originally developed by Oregon State University, develops teens as leaders and advocates for health in partnership with adults. A three-step implementation model was used including:

1. a 2-day, 12-hour train-the-trainer preparation conference for youth and adult partners statewide,

2. recruitment and training of additional youth at the community level, and

3. implementation of the identified curriculum.

A statewide training took place for teens (two from each county site) and their adult partner. The training covered topics of positive youth development via the 4-H Essential Elements (Martz, Mincemoyer, \& McNeely, 2016), youth-adult partnerships (Arnold \& Gifford, 2014), teens as teachers (Arnold, Gifford, Deen, \& Edwards, 2015), and the chosen subject matter 


\section{Teen Teacher Nutrition Outcomes}

content (nutrition). After the training, teens and adult partners returned to their communities to recruit and train additional teens who did not attend the statewide training. Communities were provided materials from the statewide training but had flexibility in how they trained additional teens. Once training was completed, teens and adult partners taught a nutrition curriculum to younger youth and provided family and community education events.

Available literature indicates cross-age teaching demonstrates positive impacts. To explore the positive outcomes of being a teen teacher further, we conducted a qualitative evaluation of the impact of serving as a teen teacher in the YA4-H! Food Smart Families (FSF) program on teen nutrition knowledge and behavior. YA4-H! was implemented within Washington State University's Extension system as a 4-H youth development program. Given the existing evidence and theoretical and conceptual foundations, we expected to find positive outcomes for teen teachers related to nutrition knowledge gain and behavior change.

\section{Program Evaluation}

The YA4-H! FSF program evaluation used a qualitative approach, incorporating focus groups and interviews, to capture the experience of being a teen teacher. Focus groups are groupbased discussions used to understand individuals' ideas and feelings about a concept. Focus groups leverage the dynamics of the group to gather rich, detailed information (Rabiee, 2004). This approach is cost-effective and efficient while providing a less structured environment that "facilitates disclosure ... and permits researchers to capture experiences and perspectives that may be less readily available via one-on-one situations" (Jones \& Broome, 2001, p. 90). When focus groups were not feasible (e.g., geographical distance, small sample size), one-on-one interviews were conducted using the same protocol for data collection.

\section{Participants}

The current sample came from a list of all teen teacher participants in the 2013-2014 YA4-H! FSF program (68\% female, $M_{a g e}=15$ years old). These 61 teens were recruited via phone, email, and face-to-face for further program evaluation. The purpose of the qualitative evaluation was to collect rich, descriptive data on the experience of being a teen teacher, thus a random sampling approach was not appropriate and all interested teens were welcome to participate. Of the 61,29 (48\%) participated either in one of four focus groups $(n=24)$ or an individual interview $(n=5)$. Comprising the current sample, these 29 teens were mostly female (59\%) and 


\section{Teen Teacher Nutrition Outcomes}

came from eight different counties throughout Washington state. The university-affiliated research office reviewed the project and found it was exempt from the need for IRB review.

\section{Procedures}

The nutrition curriculum (i.e., Choose Health Food, Fun, Fitness; Cornell University, 2014), the curriculum's intended outcomes, and prior research on teen teachers and nutrition were used to develop nutrition-related questions in the focus group and interview protocols. In addition to nutrition, questions also centered on the topics of youth-adult partnerships, the translation of teen teacher skills to job skills and other life areas, and physical activity. We will focus on the responses to questions related to nutrition questions to illustrate the impact of the program on teen health.

Focus group and interview sessions were conducted using a semi-structured protocol for consistency. Follow-up probing questions were asked at the discretion of the facilitator. The project evaluator led two focus groups and five interviews, and two county Extension faculty with direct project involvement each facilitated one focus group.

\section{Data Analysis}

Focus groups and interviews were conducted until data saturation, the point where additional data provide no new information, was achieved (Guest, Bunce, \& Johnson, 2006). Sessions were audio-recorded and transcribed verbatim by project staff. Guided by Green and colleagues' (2007) four steps to generate best qualitative evidence, we proceeded with (a) data immersion, (b) coding, (c) creating categories, and (d) identifying themes. Three project team members reviewed all transcripts (data immersion), independently coded transcripts (coding), and collectively developed an emergent coding scheme (creating categories) based on the nutrition curriculum and its intended outcomes and prior empirical work. Six additional project team members independently coded each transcript with the developed coding scheme and provided feedback to revise the codebook. Reliability was calculated as inter-coder agreement, or percent agreement for coding pairs (i.e., number of agreements divided by number of agreements plus disagreements) on $33 \%$ of transcripts randomly selected for review. Any discrepancies were reviewed with coding pairs until a threshold of at least $80 \%$ agreement was reached (Creswell, 2013). 


\section{Evaluation Results}

Table 1. Themes Discussed in Focus Groups and Interviews

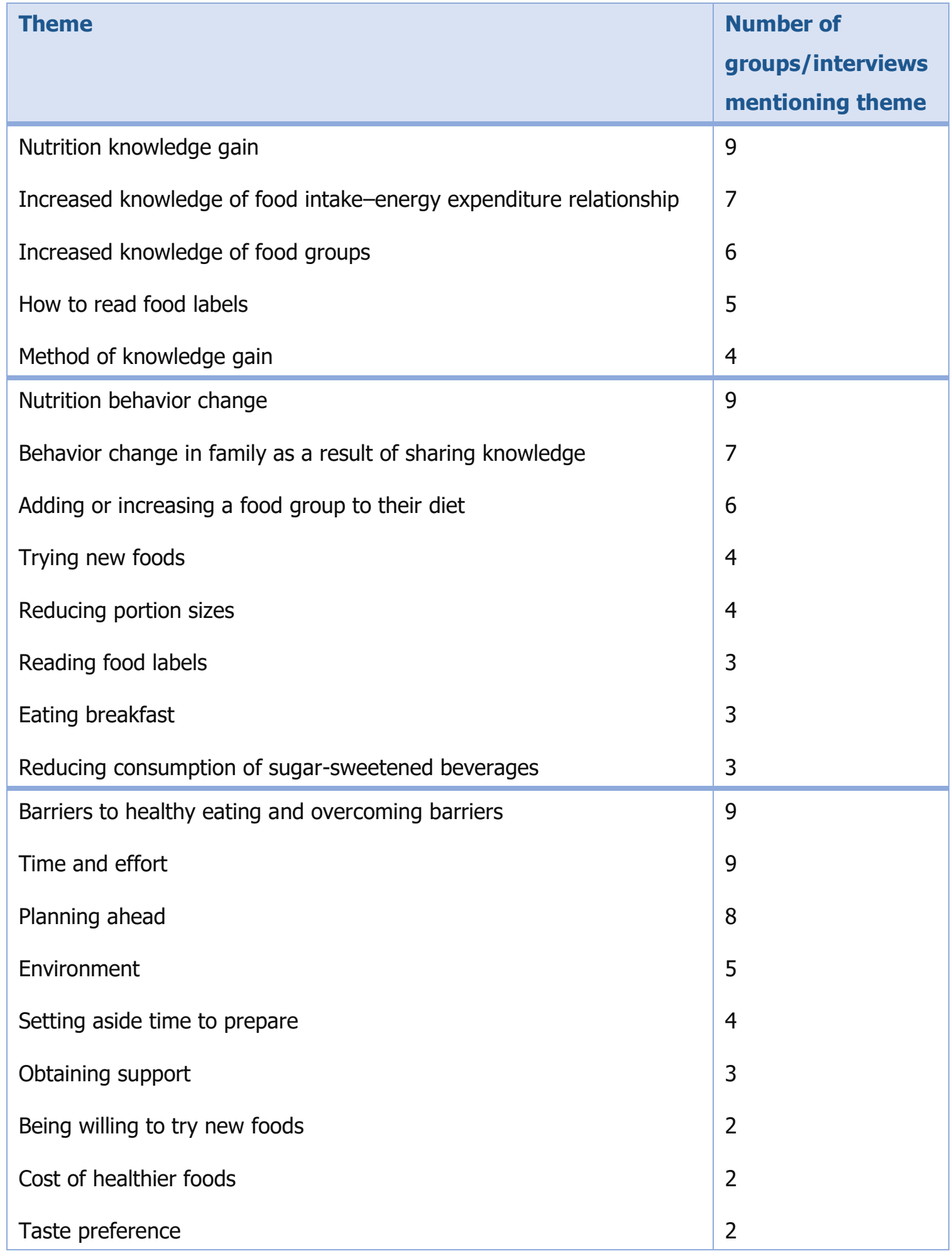

Note. Data come from four focus groups and five interviews for a maximum of nine. 
Data analysis identified themes mentioned in all focus groups and interviews related to nutrition knowledge gain and method of knowledge gain, nutrition behavior change, barriers to healthy eating, and overcoming barriers to healthy eating. Table 1 identifies sub-codes within each theme and how many focus groups or interviews mentioned each sub-code. Sub-codes provide for greater description of the properties of each theme and are reviewed in detail below with selected representative quotes.

\section{Nutrition Knowledge Gain}

Teens reported knowledge gain in relation to food labels, food groups, and the relationship between food or energy intake and physical expenditure. One teen stated "I've definitely learned a lot of things from doing [the program], like, some of the proportions . . . and a lot of ideas for healthy eating. And it also introduced me to trying cucumbers." A second teen added "I've been doing that [reading food labels] since before I was in the program, but I didn't know how to read the label well." Teens brought up using food as energy with one teen stating, "It made me think of, like, the foods you eat and how, like, you fuel your body. Like if you're eating the right types of things."

Teens reported a greater awareness of eating healthfully, in general, and how serving as a teacher contributed to their knowledge gain. One female summed up her knowledge gain by teaching, stating:

I live in a health-conscious town but I am not health conscious. Or I wasn't really. But um, actually I liked helping kids with the program and what not [and it] ended up teaching me a lot. So, I mean I, I sit down and try to make sure my breakfast has a protein and grain, whole grain, and a fruit and I try to do it. So, when I was helping them it, like, helped improve my nutrition. But I think about it and I still like, it made me think about things that I was teaching them and so, like, throughout the summer when I started teaching it and into now, I've become more health conscious about my nutrition.

Other teens attributed knowledge gain to their role as a teen teacher stating, "I didn't even know this stuff before I started teaching this." Teens spoke of how important it was to model healthy behavior and how they knew younger youth look up to them saying "It was like, oh, 


\section{Teen Teacher Nutrition Outcomes}

well I'm teaching these things about nutrition, I should also be eating nutritious food." and "[You can't] be hypocritical by telling the kids to eat breakfast when you don't."

\section{Nutrition Behavior Change}

Not only did teens indicate they gained knowledge or awareness, but they also changed their behavior related to:

- reading food labels,

- eating breakfast,

- adding or increasing a food group to their diet,

- reducing consumption of sugar-sweetened beverages,

- trying new foods, and

- reducing portion sizes.

Because of their immersion in the curriculum and teaching younger youth, teens reported that they saw a change in how they were able to internalize the new behavior changes in their daily lives. Teens stated "I can't go anywhere without, like, wanting to look at labels or something. Seeing what's inside of it. Like, I'll pick up a bottle of something and I'll look at it and be like 'How much sugar's in this'?" and "I've been trying to eat a lot more protein. Since I'm vegetarian it's hard to get protein in."

Behavior change rippled beyond the teens and into their families. Teens brought the content home as evidenced by the following exchange discussing behavior change as a result of greater attention to food labels and sugar content.

Teen 1: "Yeah, my mom even saw that and she's like, 'You can't drink soda no more."' Teen 2: "Yeah, my parents actually stopped buying it."

Teen 1: "We used to drink soda at least three days out of the week and now it's not even once a week sometimes."

\section{Barriers to Healthy Eating and Overcoming Barriers}

Teens identified a number of barriers to healthy eating and how they navigated these challenges. Barriers fell within four main areas of environment, time or effort, cost, and taste preference. Environmental barriers included availability or ease of access at home and school, availability while traveling, and living in high poverty and food-insecure communities. Teens spoke of the difficulty of consciously making nutritious choices when the availability of 
Teen Teacher Nutrition Outcomes

unhealthy, high sugar and fat options outnumber the healthy and nutritious options. For example, one teen stated "...whenever there's junk food around, you're gonna want it. That's the thing. It's just like, oh, it's here, it's fast, it's easy, it's quick." Unique situations, such as traveling, were frequently mentioned, for example, "I mean, if I'm, like, somewhere out of town, I'd probably pick up some McDonald's."

Teens shared they perceived the time and effort to prepare healthy meals and snacks was difficult, such as by this teen:

Uh, I'll tell you what gets in the way [of healthy eating], that is definitely availability. I try to meal prep the best I can but . . . that's really tough because I have to cook constantly and a lot of times I'll eat just whatever's in front of me.

In addition to the time, many teens reported that healthy foods were often more expensive. Cost factored in to food preparation and eating out, as this teen mentioned "I like restaurants and stuff. Sometimes they'll make the healthier options more expensive. So then you pay for whatever's cheaper."

Finally, although mentioned less frequently, taste was identified as a barrier to eating healthy foods. Teens mentioned cravings for less healthy food and that it tastes better exemplified in this exchange:

Teen 1: "Yeah, and you really try to, like, get a salad or something, but it's not as tasty like porridge food."

Teen 2: "Yeah and it's not as salty either."

Despite these barriers, teens developed multiple approaches to overcoming them including planning ahead, setting aside time to prepare, obtaining support, and being willing to try new foods. Most approaches centered around preparing ahead of time, which included having greater availability of healthy food, being strategic about meals, reducing access to junk food, and taking time to prep food ahead of time. For example, to reduce access to junk food at school, some teens decided not to bring spending money to school.

Interviewer: "So, what are some of the ways that you have either overcome these, or that you could overcome some of these issues? For example, that you don't have a lot of variety at school."

Teen 1: "Just not bring money." 


\section{Teen Teacher Nutrition Outcomes}

Teen 2: "Yeah, just not bring money to school."

Teen 1: "But the intentions are there, it's just that we don't go and get it or something."

\section{Discussion}

The evaluation findings presented in this paper support the use of Lee and Murdock's (2001) Teens as Teachers Essential Elements and an established curriculum for training and engaging teens as teachers (Arnold et al., 2015). Previous research finds teens who follow this structure experience positive youth development outcomes (Weybright et al., 2016). However, the evaluation also finds greater internalization of program content. Therefore, the use of teen teachers is effective in (a) educating younger youth on healthy living, (b) meaningfully engaging teens in programming, and (c) increasing knowledge and facilitating behavior change regarding curriculum content in teens. Long-term, these outcomes may result in healthier behaviors into adulthood. These evaluation results inform practice and policy related to teen nutrition education.

In addition to being effective in promoting healthy nutrition, the program aligns with the targets of youth-serving organizations, such as National 4-H, including:

- Strategic plan (U.S. Department of Agriculture, National Institute of Food and Agriculture, n.d.) that specifies

○ engaging youth in meaningful youth-adult partnerships,

- basing programs on best practices, and

- delivering programs in such a way as to maximize participation.

- Domains of professional knowledge for 4-H professionals, or the 4-H Professional Research and Knowledge Competencies (U.S. Department of Agriculture, National Institute of Food and Agriculture, 2017) of

- positive youth development,

- relationship building,

- creating and maintaining partnerships, and

- youth leadership development.

Alignment was compared with National 4-H targets due to the program being implemented in the Extension youth development system and the funding source of National 4-H Council. However, the strategic plan and professional research and knowledge competency areas align with many targets of youth-serving organizations and suggested features of positive 
Teen Teacher Nutrition Outcomes

developmental settings (Eccles \& Gootman, 2002), supporting the applicability of teen teacher programs to enhance youth health in other youth-serving organizations.

\section{Implications for Practice}

Based on our experience implementing teens as teachers, the positive outcomes documented, and previous research (e.g., Karcher, 2005), we have identified multiple practice considerations. We strongly encourage the use of an evidence-based framework, as called for by both researchers (Nation et al., 2003) and youth-serving organizations such as the National 4-H Healthy Living Task Force in 2009 (Hill, McGuire, Parker, \& Sage, 2009). Our program used Lee and Murdock's (2001) Teens as Teachers Essential Elements to guide program development and implementation. In particular, we want to focus on two of the 10 essential elements identified by Lee and Murdock: dedicated adults who support teens and initial teen training.

\section{Dedicated Adults}

Regarding adult partners, one often unspoken consideration in implementing a teens as teachers program is how resource-intensive it can be. One of these key resources is adequately trained adult partners to support each of the 10 elements. Relationships with supportive adults are one of three critical features of effective positive youth development programs (Lerner et al., 2011) and similarly, it is a critical feature of the teens as teachers model. In previous teen teaching evaluations, teens stated having a supportive adult was a benefit of the experience (Weybright et al., 2016). However, adults also need to have a foundation of knowledge and skill to support teen teachers effectively. Given this, we would revise this essential element to specify adequately trained, dedicated adults. To ensure adequate training, our program partnered teens with paid Extension faculty or staff, rather than volunteers. However, volunteers could also be appropriate adult partners with sufficient, dedicated training. Suggested training topics for adult partners include:

- Positive Youth Development

○ 4-H Essential Elements (Kress, 2005)

- Features of positive developmental settings (Eccles \& Gootman, 2002)

- Experiential education

- Do, reflect, apply (Enfield, Schmitt-McQuitty, \& Smith, 2007; Kolb, 1984)

- Youth-Adult Partnerships

- Youth voice in decision making (Zeldin, Krauss, Kim, Collura, \& Abdullah, 2016)

- Stages of youth-adult partnerships (Arnold \& Gifford, 2014)

- Benefits and challenges of youth-adult partnerships (Arnold \& Gifford, 2014) 
We incorporated these topics for both youth and adult partners into the initial training, the second Teens as Teachers essential element we highlight here.

\section{Initial Teen Training}

This Teens as Teachers essential element deserves focus, as it can potentially comprise other elements. When planning our statewide initial teen training, we had to consider all remaining elements within the initial training. For example, the training was not only for the teens but also for their supportive adult partner. Through the selection of the YA4-H! Youth Advocates for Health Teens as Teachers curriculum (Arnold, Gifford, Deen, \& Edwards, 2015), we intentionally incorporated team building sessions and content intended to set teens and adults up for successful experiences. The initial training requires thoughtful planning, as the remainder of the program will follow from this first experience for both teens and adult partners. Although Lee and Murdock (2001) specify only teens at the initial training, having both teens and their adult partners is important to develop relationships, support teens, ensure a foundation of knowledge, and provide an opportunity to begin to work together prior to content curriculum implementation. This process is supported by literature on developing effective youth-adult partnerships (Zeldin et al., 2015).

The benefit of using Lee and Murdock's (2001) Teens as Teachers Essential Elements as a framework is that it can be applied to any curriculum content. This approach is especially appropriate for other healthy living programs (e.g., Health Rocks!; National 4-H Council, 2009) where teens not only teach younger children, but also model appropriate behaviors. In addition, this approach can be expanded to include a service project such as promoting healthy offerings in a local school cafeteria.

\section{Implications for Policy}

Social cognitive theory specifies that environment influences behavior (Hoelscher et al., 2002). As such, policy changes are an important avenue to intervene and promote healthy behavior. The approach of promoting healthy behavior through targeting knowledge alone is not effective in changing youth behavior (Hoelscher et al., 2002). Instead, we should be scaling up engaging approaches, such as teens as teachers, as a widespread method to promoting both youth and teen nutrition. To do so, we have identified sample policy recommendations for various levels of implementation within youth-serving agencies including the 4- $\mathrm{H}$ system. The suggestions listed 
Teen Teacher Nutrition Outcomes

below could be implemented within a youth-serving organization's policy and procedure manual to ensure uniformity across services and make expectations clear to teens and adults.

\section{Administrative Level or State 4-H Program}

- Provide clear definitions of teen teacher role and program guidelines (e.g., follow Teens as Teachers Essential Elements).

- Require program alignment with national or professional indicators (e.g., strategic plan, competencies) to maintain standards of practice.

- At the end of each program, evaluate the teen teacher role in addition to standard program evaluation measures and use this information for performance improvement.

- Professionalize the teen teacher role. Examples include inclusion of teens in ethical codes of conduct and expectations of professional appearance (e.g., agency or program branded polo shirts).

\section{Department Level or County/Regional 4-H Program}

- Set a goal where teen teachers lead a set percentage of programs or specify programs that are led by teen teachers.

- Formalize a structure of increasing responsibility that teens can advance through. For example, teens can progress from assisting with classes, to organizing and leading, and later training other teens.

- Require teen teachers and adult partners to attend initial and ongoing training and include a module on the teen teacher role in new volunteer or employee education.

\section{Program Level or 4-H Club}

- Engage teens in program development, planning, implementation, and evaluation.

- Offer younger teens or preteens an opportunity to partner with experienced teen teachers to implement programs.

\section{Conclusion}

The results of the evaluation of the YA4-H! FSF program support and expand the limited literature on teen teachers suggesting teens not only develop skills as a result of the teaching process, such as leadership and communication (Weybright et al., 2016), but also internalize curriculum content. Although underutilized in nutrition settings, cross-age peer teaching has the potential to facilitate knowledge gain and behavior change in teens that will last into adulthood. 


\section{Teen Teacher Nutrition Outcomes}

Ultimately, this may be one effective approach in efforts to reduce adolescent and adult overweight and obesity rates. In order to disseminate cross-age peer teaching in content areas of nutrition more broadly, we recommend using previously developed curricula (e.g., Arnold, Gifford, Deen, \& Edwards, 2015) and guidelines (Lee \& Murdock, 2001) to inform and formally structure policy and practice. Future studies should continue to extend this literature by identifying the key drivers of knowledge gain and behavior change. Based on our findings, two priority research areas include better understanding the importance of structured teen training and supportive relationships with adults.

\section{Acknowledgements:}

This project was supported by a grant from National 4-H Council and Con-Agra Foods.

\section{References}

Arnold, M. E., Flesch, J. M., Ashton, C., Black, L., Brody, B., Hosty, M., \& Northway, S. (2016). YA4-H! Youth Advocates for Health: Impact of a 4-H Teens-as-Teachers Program. Journal of Extension, 54(6), n6. Retrieved from https://www.joe.org/joe/2016december/rb5.php

Arnold, M. E., \& Gifford, L. N. (2014). YA4-H! Youth advocates for health - Building successful youth-adult partnerships. Chevy Chase, MD: National 4-H Council.

Arnold, M. E., Gifford, L. N., Deen, M. K. Y., \& Edwards, J. W. (2015). YA4-H! Youth advocates for health - Teens as teachers. Chevy Chase, MD: National 4-H Council.

Bandura, A. (1977). Self-efficacy: Toward a unifying theory of behavioral change. Psychological Review, 84(2), 191.

Bandura, A. (1998). Health promotion from the perspective of social cognitive theory. Psychology and Health 13, 623-349.

Bandura, A. (2004). Health promotion by social cognitive means. Health Education \& Behavior, 31(2), 143-164.

Centers for Disease Control and Prevention. (2015). Youth risk behavior survey data. Retrieved from https://nccd.cdc.gov/youthonline/App/Default.aspx

Coleman, K., Clark, A., Shordon, M., Ocana, L., Walker, C., Araujo, R., . . Philis-Tsimikas, A. (2011). Teen peer educators and diabetes knowledge of low-income fifth frade students. Journal of Community Health, 36(1), 23-26.

Cornell University. (2014). Choose Health: Food, Fun, and Fitness. Ithaca, NY: Cornell University. 
Creswell, J. W. (2013). Qualitative inquiry and research design: Choosing among five approaches. Thousand Oaks, CA: Sage Publications.

Eccles, J. S., \& Gootman, J. A. (2002). Features of positive developmental settings. In J. S. Eccles \& J. A. Gootman (Eds.), Community programs to promote youth development. (pp. 26-120). Washington, DC: National Academies Press.

Enfield, R. P. (2001). Connections between 4-H and John Dewey's philosophy of education. Focus. Davis, CA: Center for Youth Development, University of California. Retrieved from http://www.ca4h.org/files/1234.pdf

Enfield, R. P., Schmitt-McQuitty, L., \& Smith, M. H. (2007). The development and evaluation of experiential learning workshops for 4-H volunteers. Journal of Extension, 45(1). Retrieved from https://www.joe.org/joe/2007february/a2.php

Flesch, J. M., Lile, J. R., \& Arnold, M. E. (2015). YA4-H! Youth advocates for health: Teens as teachers. Journal of Youth Development, 10(2), 121-124. Retrieved from https://jyd.pitt.edu/ojs/jyd/article/viewFile/414/400

Green, J., Willis, K., Hughes, E., Small, R., Welch, N., Gibbs, L., \& Daly, J. (2007). Generating best evidence from qualitative research: The role of data analysis. Australian and New Zealand Journal of Public Health, 31(6), 545-550. doi: 10.1111/j.1753-6405.2007.00141.x

Guest, G., Bunce, A., \& Johnson, L. (2006). How many interviews are enough?: An experiment with data saturation and variability. Field Methods, 18(1), 59-82. doi: 10.1177/1525822X05279903

Hill, L., McGuire, J., Parker, L., \& Sage, R. (2009, February). 4-H healthy living literature review and recommendations for program planning and evaluation. Retrieved from National 4-H Council website: https://4-h.org/wp-content/uploads/2016/02/4-h-healthy-living-complete-literaturereview.pdf

Hoelscher, D. M., Evans, A., Parcel, G. S., \& Kelder, S. H. (2002). Designing effective nutrition interventions for adolescents. Journal of the American Dietetic Association, 102(3), S52-S63.

Jones, F. C., \& Broome, M. E. (2001). Focus groups with African American adolescents: Enhancing recruitment and retention in intervention studies. Journal of Pediatric Nursing, 16(2), 88-96. doi: 10.1053/jpdn.2001.23151

Karcher, M. J. (2005). Cross-age peer mentoring. In D. L. Dubois \& M. J. Karcher (Eds.), Handbook of youth mentoring (pp. 266-285). Thousand Oaks, CA: Sage Publications.

Kolb, D. A. (1984). Experiential learning: Experience as the source of learning and development. Upper Saddle River, NJ: Prentice-Hall.

Kress, C. (2005). Essential elements of positive youth development. In Strengthening positive youth development environments (pp. 20-23). Madison, WI: University of Wisconsin Extension 4-H Program. 
Teen Teacher Nutrition Outcomes

Lee, F. C. H., \& Murdock, S. (2001). Teenagers as teachers program: Ten essential elements. Journal of Extension, 39(1). Retrieved from https://joe.org/joe/2001february/rb1.php

Lerner, R. M., Lerner, J. V, von Eye, A., Bowers, E. P., \& Lewin-Bizan, S. (2011). Individual and contextual bases of thriving in adolescence: A view of the issues. Journal of Adolescence, $34(6)$, 1107-1114. doi: 10.1016/j.adolescence.2011.08.001

Lobstein, T., Jackson-Leach, R., Moodie, M. L., Hall, K. D., Gortmaker, S. L., Swinburn, B. A.,... McPherson, K. (2015). Child and adolescent obesity: Part of a bigger picture. Lancet, 385(9986), 2510-2520. doi:10.1016/S0140-6736(14)61746-3

Martz, J., Mincemoyer, C., \& McNeely, N. N (2016). Essential elements of 4-H youth development programs: Curriculum and training guide. Chevy Chase, MD: National 4-H Council.

Nation, M., Crusto, C., Wandersman, A., Kumpfer, K. L., Seybolt, D., Morrissey-Kane, E., \& Davino, K. (2003). What works in prevention: Principles of effective prevention programs. American Psychologist, 58(6-7), 449-456. doi: 10.1037/0003-066X.58.6-7.449

National 4-H Council. (2009). Health Rocks! Intermediate level [4-H Health Life Series Curriculum]. Chevy Chase, MD: National 4-H Council.

Ogden, C. L., Carroll, M. D., Fryar, C. D., \& Flegal, K. M. (2015). Prevalence of obesity among adults and youth: United States 2011-2014(NCHS data brief, no. 219). Hyattsville, MD. Retrieved from https://www.cdc.gov/nchs/data/databriefs/db219.pdf

Pate, R. R., Trost, S. G., Mullis, R., Sallis, J. F., Wechsler, H., \& Brown, D. R. (2000). Community interventions to promote proper nutrition and physical activity among youth. Preventive Medicine, 31(2), S138-S149. doi:10.1006/pmed.2000.0632

Rabiee, F. (2004). Focus-group interview and data analysis. Proceedings of the Nutrition Society, 63(4), 655-660. doi: 10.1079/PNS2004399

Sawyer, S. M., Afifi, R. A., Bearinger, L. H., Blakemore, S. J., Dick, B., Ezeh, A. C., \& Patton, G. C. (2012). Adolescence: A foundation for future health. The Lancet, 379(9826), 1630-1640. doi: $10.1016 / \mathrm{S} 0140-6736(12) 60072-5$

Smith, A. (2014). Peer health teaching improves nutrition behaviors in the teen teacher population (Master's thesis). University of Nebraska, Lincoln. Retrieved from http://digitalcommons.unl.edu/nutritiondiss/48

Story, M., Lytle, L. A., Birnbaum, A. S., \& Perry, C. L. (2002). Peer-led, school-based nutrition education for young adolescents: Feasibility and process evaluation of the TEENS study. Journal of School Health, 72(3), 121-127. doi: 10.1111/j.1746-1561.2002.tb06529.x

U.S. Department of Agriculture, National Institute of Food and Agriculture. (n.d.) National 4-H strategic plan 2017. Retrieved from https://nifa.usda.gov/sites/default/files/resources/National\%204H\%20Strategic\%20Plan\%202017.pdf 
Teen Teacher Nutrition Outcomes

U.S. Department of Agriculture, National Institute of Food and Agriculture. (2017). Growing together: 4-H professional, research, knowledge and competencies 2017. Retrieved from https://nifa.usda.gov/sites/default/files/resources/4-H\%20PRKC\%202017\%20Guide.pdf

U.S. Department of Health and Human Services and U.S. Department of Agriculture. (2015, December). 2015-2020 Dietary Guidelines for Americans ( $8^{\text {th }}$ ed.). Retrieved from http://health.gov/dietaryguidelines/2015/guidelines/

Weybright, E. H., Hrncirik, L. M., White, A. J., Cummins, M. M., Deen, M. K., \& Calodich, S. (2016). "I felt really respected and I know she felt respected too": Using youth-adult partnerships to promote positive youth development in 4-H youth. Journal of Human Sciences and Extension, 4(3), 93110.

Zeldin, S., Krauss, S. E., Kim, T., Collura, J., \& Abdullah, H. (2016). Pathways to youth empowerment and community connectedness: A study of youth-adult partnership in Malaysian after-school, cocurricular programs. Journal of Youth and Adolescence, 45(8), 1638-1651. doi: 10.1007/s10964015-0320-2 